\title{
Simulation of Semiconductor Nanostructures
}

\begin{abstract}
A. Williamson, J.C. Grossman, A. Puzder, L.X. Benedict, and g.Galli
\end{abstract}

This article was submitted to International Conference on Composites Engineering, Tenerife, Spain August 5-11, 2001

\section{July 19, 2001}

U.S. Department of Energy

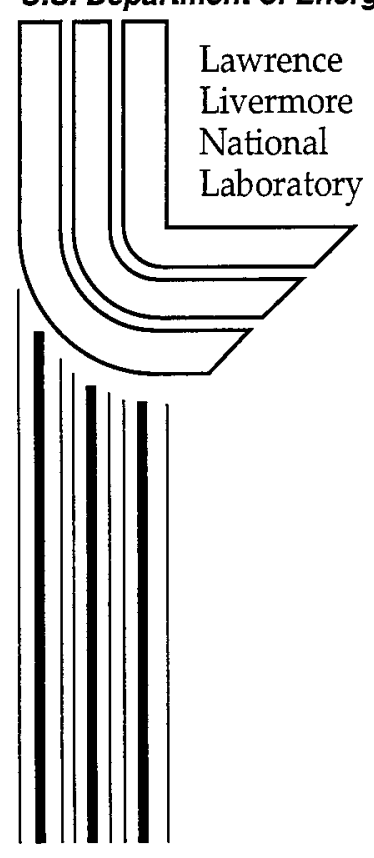




\section{DISCLAIMER}

This document was prepared as an account of work sponsored by an agency of the United States Government. Neither the United States Government nor the University of California nor any of their employees, makes any warranty, express or implied, or assumes any legal liability or responsibility for the accuracy, completeness, or usefulness of any information, apparatus, product, or process disclosed, or represents that its use would not infringe privately owned rights. Reference herein to any specific commercial product, process, or service by trade name, trademark, manufacturer, or otherwise, does not necessarily constitute or imply its endorsement, recommendation, or favoring by the United States Government or the University of California. The views and opinions of authors expressed herein do not necessarily state or reflect those of the United States Government or the University of California, and shall not be used for advertising or product endorsement purposes.

This is a preprint of a paper intended for publication in a journal or proceedings. Since changes may be made before publication, this preprint is made available with the understanding that it will not be cited or reproduced without the permission of the author.

This report has been reproduced

directly from the best available copy.

Available to DOE and DOE contractors from the

Office of Scientific and Technical Information

P.O. Box 62, Oak Ridge, TN 37831

Prices available from (423) 576-8401

http://apollo.osti.gov/bridge/

Available to the public from the National Technical Information Service

U.S. Department of Commerce 5285 Port Royal Rd., Springfield, VA 22161

http://www.ntis.gov/

OR

Lawrence Livermore National Laboratory Technical Information Department's Digital Library http://www.llnl.gov/tid/Library.html 


\title{
SIMULATION OF SEMICONDUCTOR NANOSTRUCTURES
}

\author{
A. J. Williamson, J. C. Grossman, A. Puzder, L. X. Benedict and G. Galli \\ Lawrence Livermore National Laboratory, 7000 East Ave, Livermore, CA 94550, USA
}

The field of research into the optical properties of silicon nanostructures has seen enormous growth over the last decade. The discovery that silicon nanoparticles exhibit visible photoluminescence $^{1}(\mathrm{PL})$ has led to new insights into the mechanisms responsible for such phenomena. The importance of understanding and controlling the PL properties of any silicon based material is of paramount interest to the optoelectronics industry where silicon nanoclusters could be embedded into existing silicon based circuitry.

In this talk, we present a combination of quantum Monte Carlo and density functional approaches to the calculation of the electronic, structural, and optical properties of silicon nanostructures.

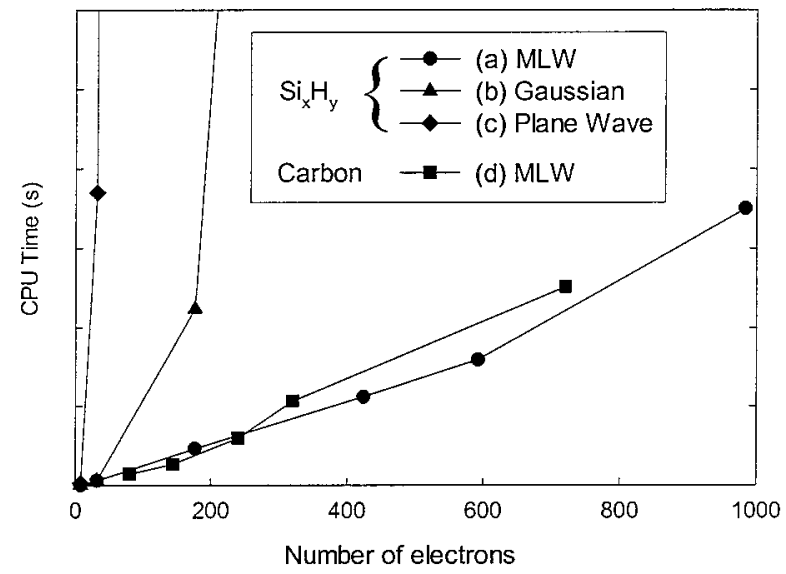

Figure 1 Time required to perform QMC total energy calculations for silicon and carbon clusters.

To enable the study of nanostructures containing several hundred atoms, we have expanded the applicability of the quantum Monte Carlo (QMC) method by developing a linear scaling QMC algorithm ${ }^{2}$ that enables accurate calculation of binding energies and optical gaps for systems containing up to 1000 electrons. In our QMC approach we use a sparse Slater determinant wavefunction constructed from Maximally Localized Wannier (MLW) orbitals. The introduction of sparsity into the Slater determinant, coupled with an efficient numerical evaluation of the MLW orbitals, improves the scaling of the QMC algorithm from scaling as $\mathrm{O}\left(\mathrm{N}^{3}\right)$, where $\mathrm{N}$ is the number of electrons, to $\mathrm{O}(\mathrm{N})$. This $\mathrm{O}(\mathrm{N})$ scaling is illustrated in Fig.1, which shows the time to calculate the total energy of hydrogenated silicon clusters and carbon fullerenes. Figure 1 shows that previous QMC implementations using (b) Gaussian and (c) plane wave orbitals scale as $\mathrm{O}\left(\mathrm{N}^{3}\right)$, whereas the MLW orbitals (a) scale with as $\mathrm{O}(\mathrm{N})$.

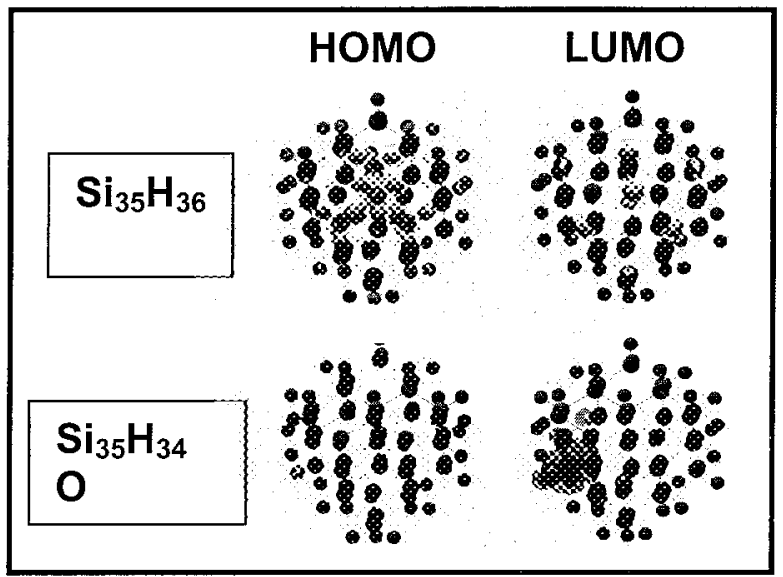

Figure 2 Charge density isosurfaces of the HOMO and LUMO of hydrogenated silicon clusters.

We combine these highly accurate QMC calculations of total energies and energy gaps with ab initio density functional (DFT) calculations using the JEEP plane wave code. We use these DFT calculations to examine structural properties and band gap trends ${ }^{3}$. In particular, we calculate optical gaps of silicon clusters with different surface passivant molecules such as oxygen, sulfur, fluorine and chlorine. All the silicon clusters are initially constructed in a diamond structure lattice with bulk Si-Si bond lengths. Dangling bonds are initially passivated with hydrogen, placed along the appropriate tetrahedral direction at the experimental Si-H distance in $\mathrm{SiH}_{4}$. The structures are then fully relaxed within the DFT calculation. 
To determine the trends in the optical properties of the clusters we consider the single particle states near the absorption edge. In Fig. 2 we plot the charge density of the highest occupied (HOMO) and lowest unoccupied (LUMO) molecular orbitals of $\mathrm{Si}_{35} \mathrm{H}_{36}$. As expected, the HOMO and LUMO densities are localized in the core of the clusters. Our LDA results (supported by our QMC calculations) show that if two hydrogens are replaced with one double bonded oxygen atom $\left(\mathrm{Si}_{35} \mathrm{H}_{34} \mathrm{O}\right)$ the band gap of this cluster closes significantly. This reduction in the gap arises from a change in the HOMO and LUMO states from core states to being localized on the surface of the cluster (see Fig. 2). These new oxygen localized states fall in the gap of the dot (see Fig. 3) reducing the gap from 3.4 to $2.2 \mathrm{eV}$.

The effect of oxygen on the gap could be due to: (i) the high electronegativity of oxygen causing it to draw charge towards the surface, (ii) the chemical environment, specifically, the existence of the double bond, or (iii) the electronic levels of the passivating atom such, as the lone pair state in oxygen, occurring inside the $\mathrm{Si}_{35} \mathrm{H}_{36}$ gap.

To test the effect of the electronegativity of the surface passivant on the gap, we calculated the gap of $\mathrm{Si}_{35} \mathrm{H}_{35} \mathrm{~F}$ and $\mathrm{S}_{35} \mathrm{H}_{35} \mathrm{Cl}$, since fluorine and chlorine have greater or comparable electronegativity to oxygen. We find that fluorine and chlorine have relatively little effect on the gap, suggesting electronegativity is not the dominant cause of the band gap reduction.

To test whether there is some other characteristic property of oxygen accounting for its attraction of charge and closing of the band gap, we passivated $\mathrm{Si}_{35} \mathrm{H}_{36}$ with an $\mathrm{OH}$ group. In this case, we observe only a slight decrease in the gap of $\mathrm{Si}_{35} \mathrm{H}_{35} \mathrm{OH}$ compared to that of $\mathrm{Si}_{35} \mathrm{H}_{36}$. It therefore appears, that neither the electronegativity of oxygen nor the lone pair state is responsible for the significant gap closing.

To test whether the effect of oxygen arises from its double bond with the surface silicon atom, we also study $\mathrm{Si}_{35} \mathrm{H}_{34} \mathrm{~S}$ by replacing two hydrogens with a sulfur atom. In a similar manner to oxygen, a large closing of the gap from $3.4 \mathrm{eV}$ to $1.8 \mathrm{eV}$ occurs (see Fig. 3) when sulfur is applied, close to the $2.2 \mathrm{eV}$ gap we see for $\mathrm{Si}_{35} \mathrm{H}_{34} \mathrm{O}$.
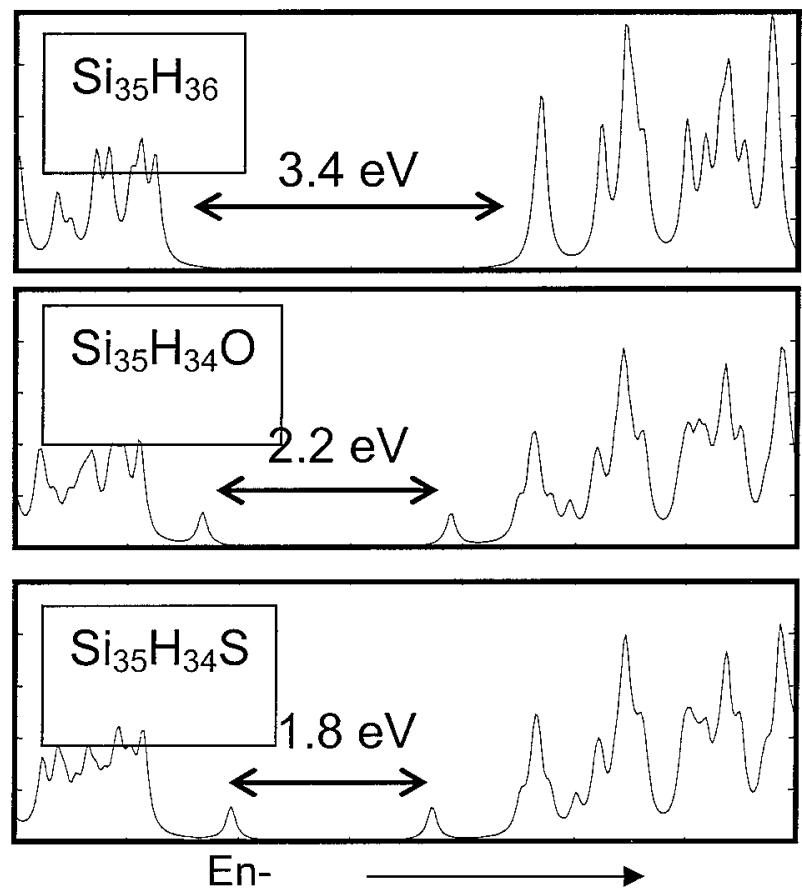

Figure 3 Density of states of silicon clusters

Therefore, our initial conclusion from QMC and DFT studies of the optical gaps of hydrogenated silicon clusters is that the dominant factor controlling the changes in the band gap with different surface passivation is the bonding character of the surface passivant.

This work was performed under the auspices of the U.S. Department of Energy by the University of California, Lawrence Livermore National Laboratory under contract No. W-7405Eng-4.

[1] S. Schuppler et al., Phys. Rev. Lett. 72, 2648 (1994).

[2] A.J. Williamson, R.Q. Hood and J.C.

Grossman, Phys. Rev. Lett. (to appear).

[3] A. Puzder, A.J. Williamson, J.C. Grossman and

G. Galli, Phys. Rev. B (submitted). 


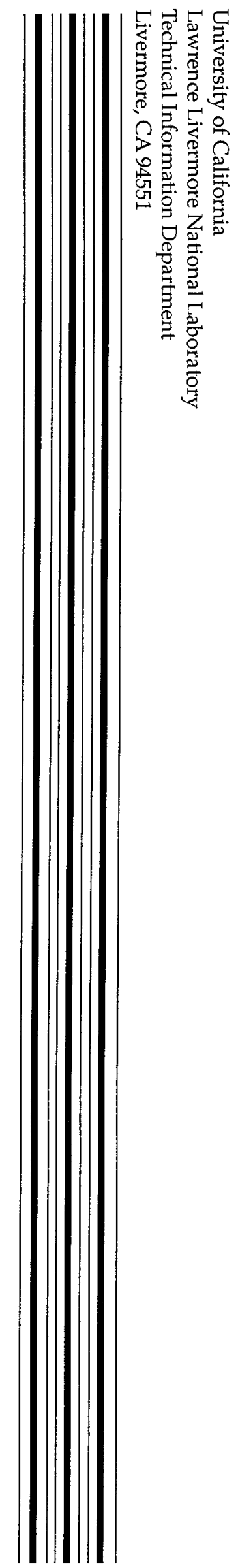

